\title{
Short communication: Screening stable flies and house flies as potential vectors of digital dermatitis in dairy cattle
}

\author{
R. J. Thibodeaux, ${ }^{1}$ J. A. Brady, ${ }^{2} \odot$ C. C. K. Maryak, ${ }^{2} \odot$ S. L. Swiger, ${ }^{3}$ and B. W. Jones ${ }^{1,2 *}$ (1) \\ ${ }^{1}$ Department of Animal Science and Veterinary Technology, Tarleton State University, Stephenville, TX 76402 \\ ${ }^{2}$ Texas A\&M AgriLife Research, Stephenville 76401 \\ ${ }^{3}$ Texas A\&M AgriLife Extension, Stephenville 76401
}

\section{ABSTRACT}

Digital dermatitis is a bacterial infection that causes lesions above the heel bulbs on cattle hooves, and several bacterial species from the genus Treponema are suspected to be causative agents of this polymicrobial condition. Transmission of the bacteria to healthy cows is understudied, particularly with regard to potential insect vectors. Therefore, the objective of this research was to determine if flies captured from a dairy farm known to have digital dermatitis are contaminated with Treponema bacteria. The DNA-based assays did not detect any Treponema phagedenis from stable flies and house flies collected at a dairy experiencing an outbreak of digital dermatitis. Other potential means of bacterial transmission are discussed.

Key words: digital dermatitis, Treponema, flies, quantitative PCR

\section{Short Communication}

Digital dermatitis is a common bacterial infection that occurs at the bulb of the hoof in cattle. This disease is more commonly found in dairy cattle but occurs in beef cattle as well. Digital dermatitis was first reported in Italy in 1974 (Cheli and Mortellaro, 1974). The lesions are very painful and can be acute or chronic. Digital dermatitis is also difficult to prevent and treat because the disease is polymicrobial. Döpfer et al. (1997) described the 4 different stages of this disease with a scoring system for each stage. Digital dermatitis is a leading cause of cattle lameness, and can lead to poor herd health, increased labor costs, and decreased production.

Beninger et al. (2018) reported the concentrations of 4 Treponema species present on digital dermatitis lesions. The species found in lesions were Treponema denticola,

Received March 17, 2020.

Accepted September 4, 2020.

*Corresponding author: bwjones@tarleton.edu
Treponema medium, Treponema pedis, and Treponema phagedenis, with T. phagedenis having a higher prevalence than the other species. However, the means of bacterial transmission to uninfected cows are not fully understood. Hoof trimming has been confirmed to be a route of mechanical vectoring (Sullivan et al., 2014). Sullivan et al. (2015) also found that the gastrointestinal tract and rectal area of ruminants might act as a reservoir for treponemes. Studies of transmission are complicated by variation in susceptibility, with some cattle free from any signs of infection, whereas others become infected, sometimes in a single hoof or multiple hooves. Some have speculated that resistance to the disease may be due to individual genetic resistance (Sullivan et al., 2014). Plummer and Krull (2017) noted that this infection is very similar to periodontal disease in humans, and that a comparative approach may provide insight for digital dermatitis research.

A vector is a living transporter and transmitter of a causative agent of disease. Vector transmission can be divided in 2 ways, biological transmission and mechanical transmission. House flies and stable flies would be labeled as mechanical vectors because they serve as a vehicle to transport the causative agent from a reservoir to a susceptible host. A biological vector, such as a mosquito, plays a vital role in the pathogen's lifecycle. If flies can be confirmed as vectors of digital dermatitis, additional insecticidal control measures can be taken to help mitigate bacterial transmission and secondary spread of the disease. Ryman et al. (2013) studied how horn flies (Haematobia irritans) influenced the spreading of mastitis in dairy cattle. This led to the question of whether flies could also transmit other bacteria such as Treponema sp. Therefore, the objective of this research was to determine if flies captured from a dairy farm affected by digital dermatitis carry $T$. phagedenis bacteria on their legs and heads.

A combination of DNA extraction and quantitative PCR (qPCR) analysis was used to determine if the bacteria were present on the flies. The common housefly (Musca domestica) and the stable fly (Stomoxys 
calcitrans) were the target species because they are the most common flies found on dairy farms. Flies ( $\mathrm{n}=$ 617) were collected on July 15, 2019, at a dairy farm in Dublin, Texas, known to have cows infected with digital dermatitis. Sterilized mesh nets were used to collect flies along the feed lines. The nets were autoclaved on the dry setting for 20 min. A fly crate was cleaned with dish soap and bleach. The same crate was then used to house the flies at the collection site. The crate was $60.9 \mathrm{~cm} \times 60.9 \mathrm{~cm} \times 60.9 \mathrm{~cm}$ with a plastic covering on one side and mesh on the rest of the sides. One side of the crate had an oval opening with a transfer sleeve attached. The net was inserted through the opening of the transfer sleeve, and the flies were released in the crate. A rubber band was used to close the sleeve opening. Once flies were collected, they were transported to a refrigerator to chill at $1^{\circ} \mathrm{C}$. All flies were then transferred to $15-\mathrm{mL}$ tubes to be stored in a freezer at $-20^{\circ} \mathrm{C}$.

Fly species were identified using a magnifying glass and segregated and counted by species (Musca domesti$c a \mathrm{n}=494$, and Stomoxys calcitrans $\mathrm{n}=123$ ). A sterile scalpel, tweezers, and cutting board were used to collect fly parts for DNA extraction. The heads and legs of the flies were collected and the 2 species were comingled in 25-mg quantities into extraction tubes according to the DNA extraction kit instructions (approximately 50 flies in each of 12 DNA extraction tubes). To decrease the chance of cross-contamination, periodic wipes with bleach on equipment were performed between groups of processed flies.

A DNeasy blood and tissue kit from Qiagen (Qiagen, Germantown, MD) was used to perform the DNA extraction. The concentration of DNA extracted from samples was measured with a Qubit 2.0 Fluorometer kit (Invitrogen by Life Technologies, Carlsbad, CA). The qPCR primers and probe used for detection were those previously developed (Beninger, et al., 2018), including T. phagedenis forward 5'-CCCGCAGGAAGGTATAATC-3', T. phagedenis reverse 5'-CACAGCTGTTGTGGTATTAAG-3', and T. phagedenis probe 5'-FAMAATCCGCCTACGACTGCGATACCA-BHQ1-3', that produce a 90-bp amplicon. Each qPCR reaction contained $12.5 \mu \mathrm{L}$ of $2 \mathrm{X}$ Kapa2G Robust ReadyMix (Roche Diagnostics, Indianapolis, IN), $250 \mathrm{n} M$ forward primer, $250 \mathrm{n} M$ reverse primer, $250 \mathrm{n} M$ probe, and $2.5-\mu \mathrm{L}$ DNA from the extraction. A positive control sequence used for $\mathrm{qPCR}$ consisted of the T. phagedenis 90-bp DNA amplicon cloned into plasmid pCR2.1 TOPO, then used for detection in qPCR reactions. The qPCR protocol was $15 \mathrm{~min}$ at $95^{\circ} \mathrm{C}$, followed by 35 cycles of 30 s at $94^{\circ} \mathrm{C}, 20 \mathrm{~s}$ at $57^{\circ} \mathrm{C}$, and $20 \mathrm{~s}$ at $72^{\circ} \mathrm{C}$. Each DNA extraction was used to conduct 3 qPCR replicates. Treponema phagedenis was selected for detection be- cause this species had the highest concentration among all stages of the infections (Nielsen et al., 2016) and was present in $100 \%(\mathrm{n}=4)$ of sampled digital dermatitis lesions from infected cows at the dairy being studied. Each qPCR instrument run also contained a negative control consisting of molecular grade water added to a qPCR reaction to assess potential contamination of the reagent master mix. A second positive control $\mathrm{qPCR}$ reaction was conducted to confirm that the DNA from the extractions was of suitable quality for qPCR amplification. This positive control qPCR reaction detected Escherichia coli DNA. Because E. coli is a common bovine fecal microbe, it was assumed to contaminate flies at a dairy facility. The qPCR reaction components for $E$. coli were identical to the T. phagedenis detection reactions, except that an annealing temperature of $60^{\circ} \mathrm{C}$ was used instead of $57^{\circ} \mathrm{C}$, and the primers were EC23S857F 5'-GGTAGAGCACTGTTTTGGCA-3' and EC23S857R 5'-TGTCTCCCGTGATAACTTTCTC-3', along with the probe EC23S857P 5'-FAM-AATCCGCCTACGACTGCGATACCA-BHQ1-3' (Chern et al., 2011).

The qPCR reactions did not detect the presence of $T$. phagedenis bacteria in any of the fly samples, whereas hoof lesions sampled from the dairy were $100 \%$ contaminated with T. phagedenis (Figure 1). The control qPCR reactions detected E. coli DNA in $100 \%$ of fly samples, indicating the fly DNA extractions were of sufficient quality to detect bacterial DNA targets by qPCR. The sample size $(n=617)$ collected was small relative to the total population size of the flies at the dairy. Sample size was chosen to be a representative sample of the flies at the dairy. Previous studies have captured between 50 and 1,650 flies (Szostakowska et al., 2004; Xu et al., 2018), so it was determined that the current sample size was an appropriate representative sample. It is possible that flies are a vector for the bacteria and our sampling efforts did not capture contaminated flies or that the level of contamination with T. phagedenis in captured flies was so low or rare (or both) as to be undetectable by qPCR (Kralik and Ricchi, 2017). However, the dairy in the study had a high incidence of digital dermatitis, 20\% (Wells et al., 1999). Lesions sampled from the dairy were contaminated with T. phagedenis as determined by $\mathrm{qPCR}$, and no flies were found to be contaminated with $T$. phagedenis. One pitfall to the study is the low number of lesions sampled. Also, no information to our knowledge exists on infectious dose of T. phagedenis. Therefore, it is unlikely that a large number of flies carry Treponema at dairies with digital dermatitis. In the future, perhaps observing and collecting flies that have landed on the cattle directly would provide better insight on whether flies may serve as potential vectors. It is possible that 


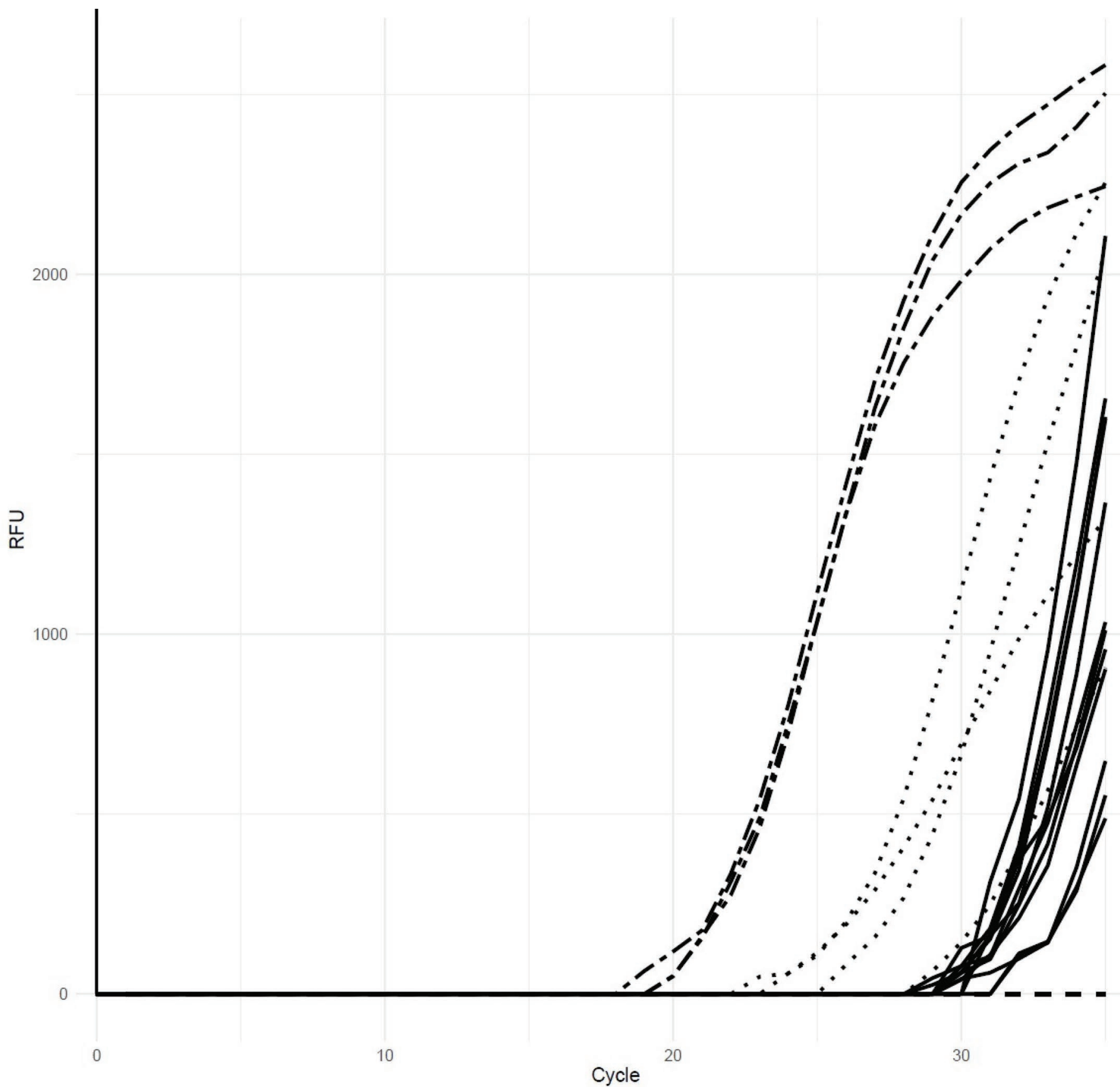

Figure 1. Detection of Treponema phagedenis and Escherichia coli by quantitative PCR (qPCR). Treponema phagedenis qPCR positive control, dotted and dashed lines $(\mathrm{n}=3)$; T. phagedenis $\mathrm{qPCR}$ on hoof samples, dotted lines $(\mathrm{n}=4) ;$ E. coli $\mathrm{qPCR}$ on samples of 50 pooled flies, solid lines $(\mathrm{n}=12$, all amplified close to cycle 30); T. phagedenis $\mathrm{qPCR}$ on samples of 50 pooled flies, dashed lines $[\mathrm{n}=12$, largely obscured by solid line at 0 relative fluorescence units (RFU), no amplification in any sample]. For all samples, only one qPCR repetition is shown out of 3 conducted. Treponema phagedenis negative control $\mathrm{qPCR}(\mathrm{n}=3)$ did not amplify (curves not shown).

flies are not a significant vector for Treponema that cause digital dermatitis. Additional research should concentrate on other likely mechanical vectors of digital dermatitis such as feces exposure, hoof trimming equipment, and walking path obstructions.

\section{ACKNOWLEDGMENTS}

We thank the members of Texas A\&M AgriLife Research for their assistance and resources, as well as the Tarleton State University Office of Research and In- 
novation for their funding (Grant \# 1902411). Thanks also go to the producer for their support. The authors have not stated any conflicts of interest.

\section{REFERENCES}

Beninger, C., S. A. Naqvi, S. Naushad, K. Orsel, C. Luby, H. Derakhshani, E. Khafipour, and J. De Buck. 2018. Associations between digital dermatitis lesion grades in dairy cattle and the quantities of four Treponema species. Vet. Res. 49:111. https://doi.org/10.1186/ s13567-018-0605-z.

Cheli, R., and C. Mortellaro. 1974. Digital dermatitis in cattle. Pages 208-213 in 8th International Conference on Diseases of Cattle, Milan, Italy. Piacentina Gallarati, Piacenza, Italy.

Chern, E. C., S. Siefring, J. Paar, M. Doolittle, and R. A. Haugland. 2011. Comparison of quantitative PCR assays for Escherichia coli targeting ribosomal RNA and single copy genes. Lett. Appl. Microbiol. 52:298-306. https://doi.org/10.1111/j.1472-765X.2010 .03001.x.

Döpfer, D., A. Koopmans, F. A. Meijer, I. Szakall, Y. H. Schukken, W. Klee, R. B. Bosma, J. L. Cornelisse, A. J. A. M. van Asten, and A. A. H. M. ter Huurne. 1997. Histological and bacteriological evaluation of digital dermatitis in cattle, with special reference to spirochaetes and Campylobacter faecalis. Vet. Rec. 140:620-623.

Kralik, P., and M. Ricchi. 2017. A basic guide to real time PCR in microbial diagnostics: Definitions, parameters, and everything. Front. Microbiol. 8:108. https://doi.org/10.3389/fmicb.2017.00108.

Nielsen, M. W., M. L. Strube, A. Isbrand, W. D. H. M. Al-Medrasi, M. Boye, T. Jensen, and K. Klitgaard. 2016. Potential bacterial core species associated with digital dermatitis in cattle herds identified by molecular profiling of interdigital skin samples. Vet. Microbiol. 186:139-149. https://doi.org/10.1016/j.vetmic.2016.03.003.

Plummer, P. J., and A. Krull. 2017. Clinical perspectives of digital dermatitis on dairy and beef cattle. Vet. Clin. North Am. Food Anim. Pract. 33:165-181. https://doi.org/10.1016/j.cvfa.2017.02.002.
Ryman, V. E., S. C. Nickerson, D. J. Hurley, R. D. Burghaus, and F. M. Kautz. 2013. Influence of horn flies (Haematobia irritans) on teat skin condition, intramammary infection, and serum anti- $S$. aureus antibody titers in Holstein heifers. Res. Vet. Sci. 95:343346. https://doi.org/10.1016/j.rvsc.2013.04.017.

Sullivan, L. E., R. W. Blowey, S. D. Carter, J. S. Duncan, D. H. GroveWhite, P. Page, T. Iveson, J. W. Angell, and N. J. Evans. 2014. Presence of digital dermatitis treponemes on cattle and sheep hoof trimming equipment. Vet. Rec. 175:201. https://doi.org/10.1136/ vr.102269.

Sullivan, L. E., S. D. Carter, J. S. Duncan, D. H. Grove-White, J. W. Angell, and N. J. Evans. 2015. The gastrointestinal tract as a potential infection reservoir of digital dermatitis-associated treponemes in beef cattle and sheep. Appl. Environ. Microbiol. 81:74607469. https://doi.org/10.1128/AEM.01956-15.

Szostakowska, B., W. Kruminis-Lozowska, M. Racewicz, R. Knight, L. Tamang, P. Myjak, and T. K. Graczyk. 2004. Cryptosporidium parvum and Giardia lamblia recovered from flies on a cattle farm and in a landfill. Appl. Environ. Microbiol. 70:3742-3744. https:// doi.org/10.1128/AEM.70.6.3742-3744.2004.

Wells, S. J., L. P. Garber, and B. A. Wagner. 1999. Papillomatous digital dermatitis and associated risk factors in US dairy herds. Prev. Vet. Med. 38:11-24. https://doi.org/10.1016/S0167-5877(98)00132 $-9$.

Xu, Y., S. Tao, N. Hinkle, M. Harrison, and J. Chen. 2018. Salmonella, including antibiotic-resistant Salmonella, from flies captured from cattle farms in Georgia U.S.A. Sci. Total Environ. 616-617:90-96. https://doi.org/10.1016/j.scitotenv.2017.10.324.

\section{ORCIDS}

J. A. Brady @ https://orcid.org/0000-0002-3739-4432

C. C. K. Maryak @ https://orcid.org/0000-0002-4723-3376

B. W. Jones (1) https://orcid.org/0000-0002-1904-2396 